\title{
Study of the Relationship between Organizational Silence, Job Exhaustion and Job Performance among Farshousing Bank Staff
}

\author{
Leila Taheri ${ }^{1} \&$ Reza Zarei ${ }^{1}$ \\ ${ }^{1}$ Department of Educational Management, Marvdasht Branch, Islamic Azad University, Marvdasht, Iran \\ Correspondence: Reza Zarei, Department of Educational Management, Marvdasht Branch, Islamic Azad \\ University, Marvdasht, Iran. Tel: 98-917-712-7958. E-mail: Zareireza955@gmail.com
}

Received: October 19, 2016

Accepted: October 27, 2016

Online Published: February 7, 2017

doi:10.5539/res.v9n1p176

URL: http://dx.doi.org/10.5539/res.v9n1p176

\begin{abstract}
The aim of this study was to investigate the relationship between organizational silence, job exhaustion and job performance. It was a correlationstudy. The sample population included 642 employees of the Housing Bank of Fars province. Selection of the participants was carried out using a single-stage cluster sampling method and 133 subjects were selected as sample. In this study, three questionnaires including: job performance (Patterson, 1970), job exhaustion (Maslach \& Jackson, 1981) and organizational silence (Vakvla \& Bvradas, 2005) were used to collect data. Pearson correlation coefficient, stepwise regression analysis, mean, and standard deviation, were used to analyze the data. The result indicated that job performance and job exhaustion have a negative and significantcorrelation with institutional performance, among them, organizational silence, attitude of the headmaster towards the silence, and the prospect of higher management towards silence can reversely predict job performance and dimensions related to the communication opportunitieshave direct relationship with performance. Also, among the dimensions of job exhaustion, the dimension of reduction of personal success has a more effective role in job exhaustion of housing bank employees.
\end{abstract}

Keywords: job performance, job exhaustion, organizational silence

\section{Introduction}

Undoubtedly, skilled and efficient work force is one of the major tools to attain organizational goals (Ostovar \& Amir Zadehkhatoon, 1387). Job performance has been one of the effective factors in organizations which has been an importance part of organizational and institutional studies (Eshoo et al., 1388). One of the most discussed topics on organizational issues, is rooted on the proper understanding of the reasons for job performance which includes assigned duties related to job performances (Farokhnezhad et al., 1390). The job performance of the individuals is very important to the organizational survival which can be considered as the most important result of the job activities (Callbirth \& Concer, 2008).

Organizations growingly demand their staff to be innovative, to express their ideas and to be responsible for the excessive expectations of the customers focus on the quality as a an indicator of changing world (Qvine \& Spritser, 1997). One of the major problems that organizations are currently, especially human resources departments are dealing with, is the unwillingness of employees to participate in corporate discussions. Most of the employees are reclusive and practically are unwilling to express their ideas. Unfortunately some of the managers don't care about this issue and they regardthe unwillingness of the employees in participating in discussion as a kind of organizational satisfaction. However, according to the novel theories of the management, it should be noticed that discussion is one of the important approaches in distribution of the knowledge. Therefore, as the number of reticent employees in an organization increases, it is expected that the ground for creativity, innovation and efficiency of the organization decreases. In another words, one of the main features of the healthy organization, is that the physical and psychological health of the employees should be regarded with attention and care by the managers as important as production and efficiency. In order to adapt to the social and occupational environment, human being, in the present century, is compelled to endure some restrictions and pressures, thus, it is possible that the job may raise dissatisfactions and incompatibilities distracting the individuals from the common and normal routines. Undoubtedly, the management of the banks is not excluded from this issue and it is necessary that the senior managers of the banksdevote much energy and care to design programs in order to prevent disorders in organizations like job exhaustion. 
Therefore, the size, structure and efficiency of the banking sector, which is independent dimensions of financial development, the focus of attention.

If an employee is silent, overall performance suffers (Bagheri et al., 2012). The organizational silence and find ways to resolve issues that have great importance in the organization.

Due to the close connection between the customers and the employees of the banks and exchange of money, there is always some worries at the ending hours of the day which imposes much pressure to these people. Therefore, according to the type of activities of these people, it seems that they may face job exhaustion. Banks play an essential role in the most of the economies; because they are the center of financial system and have the responsibility of the payments. Consequently, size, structure, and efficiency of the banking sector which is an independent part of financial development are under scrutiny.

If an employee keeps silence, the total efficiency of him will decrease (Bageri et al., 2011). These days, organizational silence, and ways of dealing with it have great importance in organizational discussions. Employees who have a determining role in giving services and establishing a relationship with customers and their attitude and behavior of the employees towards customers affect the satisfaction the quality of the services which, in its turn are effective in the improvement of organizational performance (Menoon \& Lart, 2004).

Since these individuals have to satisfy both demands and requirements of the customers and also answer to the desires of the organizations they suffer from job exhaustion which is one of the forms of psychological pressure (Arnnet et al., 2006). On the other hand, it is also proven that experts who ate required to have more interactions with the customers are more prone to this syndrome (Dambersecis et al., 2011). A person having job exhaustion and suffer from impaired physical, emotional and attitudinal fatigue, he feels no improvements and his performance declines (Abdoli Masoleh, 1386).

Regarding the special problems of the employees of the organizations andfinancial institutes of the country like banks, such as high sensitivity of the job due to involvement with the properties of the people, movement restrictions, interaction with people of deferent social class with different ideologies and expectations are vulnerable to job exhaustion (Razmi \& Nemati, 1390).

Since, job exhaustion also causes a decline in the quality of the services provided to the customers and clients and thus dissatisfaction with the services, understanding and prevention of job exhaustion will be effective in the promoting psychological health of the individuals and the level of the quality of the services (Sharman, 2004). On the other hand, being in competitive environment for thefinancial banks and the necessity of the winning in this environment which is having healthy, ensuthiastic, and energetic employees who serve high quality of services to the customers and clients with high spirit and motivation. It is another factor which indicates that the attempts in prevention of job exhaustion contribute to the succeeding of the banks in this competitive new environment. Some studies have been carried out in western countries on the effects of factors such as personality, hope, work stress, on the performance in banking sectors. The number of the study in our country is so limited. So far no studies have been carried out in the field of exhaustion and organizational silence on the performance of bank employees. The findings of these limited number of studies show that a great percent of bank employees experience high level of job exhaustion. Thus, the present study investigates the effects of exhaustion and organizational silence on the job performance of the housing bank staff.

\subsection{Research Hypothesis}

There is a significant relationship between organizational silence and job exhaustion.

Sub-hypotheses:

1) There is a significant relationship between the dimensions of organizational silence and job performance.

2) There is a significant relationship between dimensions of job exhaustion and performance.

3) Dimensions of organizational silence can significantly predict job performance.

4) Dimensions of exhaustion cansignificantly predict job performance.

5) Job exhaustion and organizational silence are able to predict job performance.

\section{Method}

Based on its goal, the present study is a functional study and based on data collection approach it is a correlation study. The samplepopulation of this study includes all official and contracted employees and managers from different sections of housing bank in Fars in 1394 consisted of 642 persons. The sampling method was random single step clustering in a way that among all regions of the Fars province 10 towns were randomly selected then 
questionnaire was sent to and collected from sectors. For data collection three questionnaires were used namely: job performance questioarie (Paterson, 1970), organizational silence questionnaire (vacvala \& vBoradas, 2005), job exhaustion questionnaire (Meselch \& Jckson, 1981). The purpose of the study in terms of applied research and the way of gathering information is a correlation research. Pearson correlation coefficient and regression were used for data analysis.

\section{Results}

The main hypothesis: there is a significant relationship between organizational silence, exhaustion and job performance.

Table 1. Correlation matrix of organizational silence, job exhaustion and job performance

\begin{tabular}{ccc}
\hline & Job exhaustion & Organizational silence \\
\hline Job performance & $0.45^{* *}$ & $0.23^{* *}$ \\
\hline
\end{tabular}

It can be concluded from the output of the Table 1 that organizational silence and job exhaustion have significantly inverse correlation, in less 0.01 , with job performance.

First sub- hypothesis: there is a significant relationship between the dimensions of organizational silence and job performance.

Table 2. Correlation matrix of organizational silence and job performance

\begin{tabular}{cccc}
\hline & Communication opportunities & Attitude of the supervisor to silence & Attitudes of high manage net to silence \\
\hline Job performance & $0.41^{* *}$ & $0.40^{* *}$ & $0.38^{* *}$ \\
\hline
\end{tabular}

It can be concluded from the Table 2 that among the dimensions of organizational silence, the dimension of higher management's attitude towards silence has a significantly reverse correlation with job performance and there is a direct significant correlation between communication opportunities and job performance in 0.01 level of significance.

Second sub-hypothesis: there is a significant relationship between dimensions of exhaustion and job performance.

Table 3. Correlation matrix of job exhaustion and job performance

\begin{tabular}{cccc}
\hline & Reduction in personal success & Depersonalization & Emotional exhaustion \\
\hline Job performance & $0.4^{* *}$ & 0.3 & 0.9 \\
\hline
\end{tabular}

It can concluded from the output of Table 3 that among the dimensions of exhaustion only the dimension of reduction in personal success has significantly direct correlation with job performance.

Third sub-hypothesis: the dimensions of organizational silence can significantly predict job performance.

Table 4. The result of regression analysis of job performance based on dimensions of organizational silence in stepwise fashion

\begin{tabular}{|c|c|c|c|c|c|c|c|c|c|c|}
\hline Step & variablecriterion & Predictor valuables & beta & $\mathrm{t}$ & $\mathrm{p}$ & $\mathrm{R}$ & $\mathrm{R}^{2}$ & $\mathrm{~F}$ & df & $\mathrm{p}$ \\
\hline First & Job performance & $\begin{array}{c}\text { Communication } \\
\text { opportunities }\end{array}$ & 0.14 & 5.3 & 0.001 & 0.45 & 0.17 & 28.13 & $1 ، 134$ & 0.001 \\
\hline Second & Job performance & $\begin{array}{c}\text { Communication } \\
\text { opportunities }\end{array}$ & 0.29 & 3.16 & 0.002 & 0.45 & 0.21 & 17.63 & $2 \cdot 133$ & 0.001 \\
\hline
\end{tabular}


In Table 4 if interventions or experimental manipulations were used, provide evidence on whether they were delivered as intended. In basic experimental research, this might be the results of checks on the manipulation. In applied research, this might be, for example, records and observations of intervention delivery sessions and attendance records.

Table 5. The result of stepwise regression on the analysis of job performance based on jobexhaustion dimensions

\begin{tabular}{cccccccccccc}
\hline Step & Criterion variable & Predictor valuables & beta & $\mathrm{p}$ & $\mathrm{df}$ & $\mathrm{F}$ & $\mathrm{R}^{2}$ & $\mathrm{R}$ & $\mathrm{p}$ & $\mathrm{t}$ \\
\hline \multirow{2}{*}{ First } & Job performance & $\begin{array}{c}\text { Reduction of } \\
\text { personal success }\end{array}$ & 0.41 & 0.001 & 1.134 & 26.03 & 0.16 & 0.40 & 0.001 & 5.1 \\
\hline
\end{tabular}

It can be concluded from the test results in Table $5,[F(1,134)=26 / 03, p<0 / 01]$ that a significant linear relationship exists between predictor variables (dimensions of exhaustion syndrome) and the dimensions of exhaustion syndrome are significantly able to predict job performance.

Fifth sub-hypothesis: job exhaustion and organizational silence are able to predict job performance.

Table 6. Stepwise regression analysis of job performance and job based on job exhaustion and organizational silence

\begin{tabular}{|c|c|c|c|c|c|c|c|c|c|c|}
\hline step & $\begin{array}{l}\text { Criterion } \\
\text { variable }\end{array}$ & Predictor variables & $\mathrm{p}$ & $\mathrm{df}$ & $\mathrm{F}$ & $\mathrm{R}^{2}$ & $\mathrm{R}$ & $\mathrm{p}$ & $\mathrm{t}$ & bête \\
\hline first & $\begin{array}{c}\text { Job } \\
\text { performance }\end{array}$ & Organizational silence & 0.001 & $1 ، 134$ & 34.43 & 0.20 & 0.45 & 0.001 & -5.86 & -0.45 \\
\hline second & $\begin{array}{c}\text { Job } \\
\text { performance }\end{array}$ & Organizational silence & 0.001 & $2 \cdot 133$ & 31.47 & 0.32 & 0.56 & $\begin{array}{l}0.001 \\
0.001\end{array}$ & $\begin{array}{l}-7.23 \\
4.78-\end{array}$ & 0.053 \\
\hline
\end{tabular}

It can be concluded from analysis of variance of second step test results in Table $6,[\mathrm{f}(2,133)=31 / 47, \mathrm{p}<0 / 01]$ that between predictor variables (Job Exhaustion and Organizational Silence). There is a significant linear relationship and job exhaustion can significantly predict job performance and organizational silence in reverse.

\section{Discussion}

The main hypothesis: according to the findings of the study, we conclude that there is a negatively reverse correlation between job exhaustion and organizational silence. This finding is in the same vein with the findings of Cherniss (1995), Moris Milicon(2000), sieh et al. (2004), Gonzalez and Bernard (2006), Sahytglov and Zaheer (2010), Achilles and Red (2011), Alarcon (2011), Baker and Costa (2014), Mohaymani (1392), Abbas and colleagues (1394). In determining this hypothesis, it can expressed that one of the cases managers must take into account encountering human resources is the promotion in the expressing ideas, offering suggestions, and criticisms and establishing more interaction with the employees till they can propose their criticism and suggestions aligned with promoting work facilities and increase performance of the employees. Deficiency and lack of organizational cooperation, creates a situation in which just a few number of individuals know what to do to generate changes. Consequently, this condition will have undesired output and failure which can include poor organizational performance.

First hypothesis: based on the findings of the study, it can be deducted that there is reverse significant relationship among the dimensions of organizational silence, dimensions of supervisor's attitude and high management towards silence with job performance and there is a significantly positive correlation between communication opportunities and job performance in levels less that $0 / 01$. This finding is aligned with the result 
of previous studies by Dmytrys and Vakvla (2007), Sahytglv and Zaheer (2010), Nicolas and colleagues (2011), Zuhair and Erdogan (2011), Mohaymani (1392), Doosdar and colleagues (1393), Bozorgnia Hosseini and Enayati (1393), Abbas and colleagues (1394).

To elaborate on this hypothesis it can be remarked that an employee as a mature person who is knowledgeable enough perceives criticism and expressing of the opinions as an individual's right and tends to participate in the management of learning organization. Employees of the banking system don't have sufficient incentive to participate and express their ideas in organizational decision-making; this lack of motivation in the banking system has led to increased organizational silence. Such a feeling of inability to express their ideas, obsessions and problems in employees affects their performance and decreases their efficiency in the organization, eventually becomes a detriment to the organization.

The second hypothesis: the results show that the current situation job exhaustion of the employees is affected were by the decline in personal success, components of emotional exhaustion and depersonalization as the last factor; in other words, according to the average exhaustion score, it can be said reduction component of personal accomplishment has more effective role in the outbreak of exhaustion in staff housing bank. This part of the findings is aligned with the results of the studies by Bank (2003), Sherman (2004), Shuffle (2005), Maslach and Jackson (1981), aux Pins and Knyan (2005), Watson (2008), Shyrm (2004), Baker and Costa (2014), Dmrty and colleagues (2014), Gamba and Soria (2014), Lmrdany Someh (1394), but it is not consistent with part of the results of Elite and trim's study (2004). The obtained results regarding the amount of job exhaustion and its analysis on triple emotional, depersonization, reduction of personal achievement dimensions, indicated that, the condition of this variable is such that a negligence of itand not devoting much attention to empower human resources will lead to decline in efficiency and consequently loss of the ability to compete in competitive atmosphere. Because the most important competitive advantage of successful organizations, in this privileged environment, is because of healthy and capable human resources.

The third sub-hypothesis: according to the findings of this study, it was found out that among the dimensions of organizational silence, the dimension of communication opportunities directly, and the attitude of high management towards silence in reverse fashion, can significantly predict the performance but the dimension of the attitude of supervisor towards silence cannot significantly predict productivity. The findings of this study is aligned with results of previous studies by Abbasi et al. (1394), Zuhair and Erdogan (2011), Sahytglv and Zaheer (2010) and Mohaymani (1392).

To specify this hypothesis it can be said that organizational silence is of complex multi-dimensional. Silence can be conscious, deliberate, and goal-oriented. According to their organizational maturity, expertise, and scientific power, employees see cooperation in decision making and proposing of suggestions and expressing of the ideas as their rights in a learner organization and don't have positive attitude towards silence.

The fourth sub-hypothesis: the findings show that there is asignificant linear relationship between predictor variables (dimension of exhaustion syndrome) and exhaustion syndrome is significantly able to predict job performance.

Among dimensions of exhaustion syndrome, only the reduction in personal success directly, can predict job performance and other aspects have not a significant impact in anticipating productivity. The results are aligned with the studies by Baker and Democrat (2014), Gamba and Soria (2014), Demrty and colleagues (2014), Shuffle and Bank (2003) and Pins and Kinyan (2005).

Bank staffs typically face high workload, multiple deadline, and excessive time pressure. Therefore, they face a large number of inner organization and out of organization individuals who demand a vast spectrum of needs and expectations. Meeting these diverse and numerous demands, naturally, creates situations, in case of not identifying on time and inappropriate dealing with them may lead to job exhaustion.

Fifth sub-hypothesis: according to research findings it was concluded that organizational silence and exhaustion predict performance in reverse fashion. This means that by increasing organizational silence and exhaustion the employee's performance reduces. This result is consistent with the results studies by Karaca (2013), Baker and Costa (2014), Arshadi and colleagues (1392), Jaefary and colleagues (1392), Bozorgnia Hosseini et al. (1393), Marvian, Hosseini et al. (1394). The managers must take this point into consideration when the employees are satisfied with their job and have delighted feelings their work place, and instead of silence organizational voice exists in the organization. If the employees have freedom in expressing their ideas, criticisms and suggestion, the ground will get ready for the quantitative and qualitative promotion of the job. The employee's silence take place when they restrain themselves from presenting their ideas, beliefs and concerns about work related problems and issues. Therefore the managers should know that human forces is the most important capital in the organization 
and it is necessary to select solutions suitable for motivating, creating work satisfaction, enhancing creativity, freedom in expressing ideas and cooperating in decision making and eventually, increasing of the efficiency and effectiveness.

\section{References}

Alagehmand, E. (2003). General Management (p. 195). Tehran.

Argyris, C. (1977). Double loop learning in organizations. Harvard Business Review, 55, 115-125.

Barati, H., Arizi, H. R., \& Khora, A. (2009). Relationship between organizational justice and job performance in Esfahan Steel Company. Journal of Outlook Management, 33, 28-29.

Bies, R. J., \& Tripp, T. M. (1999). Two faces of the powerless: Coping with tyranny. In R. M. Kramer, \& M. A. Neale (Eds.), Power and influence in organizations (1st ed., pp. 203-219). Thousand Oaks: Sage.

Borman, W. C., \& Motowidlo, S. J. (1997). Task performance and contextual performance: The meaning for personnel selection research. Hum Perform, 10(2), 99-109. https://doi.org/10.1207/s15327043hup1002_3

Farahbakhsh, S. (2011). The relationship between different dimensions of exhaustion and job-related factors in managers. Government agencies of Lorestan province. Behavioral Science Research, 9, 56-62.

Keshavarzi, S. (2008). The study of relationship between leadership style of the managers (transformercooperative) and work exhaustion of school teachers of the four zones (Master's thesis). Faculty of Education and Psychology, University of Shiraz.

Liu, D., Wu, J., \& Ma, J. (2009). Organizational silence: A survey on employees working in a telecommunication company (pp. 1647-1651). Proceeding of 40th International Conference on Computers \& Industrial Engineering, Troyes, France. https://doi.org/10.1109/iccie.2009.5223551

Mahdad, A. (2008). Psychology of work force. Isfahan: Jangal publication, Chapavl.

Maslach, C., \& Jakson, S. E. (1981). The Measurement of Experienced Burnout. Journal of Occupational Behavior, 2, 99-113. https://doi.org/10.1002/job.4030020205

Mirsepassi, N. (2002). Strategic management of human resource and labor relations (p. 484). Tehran: Mir Publication.

Nemeth, C. J., \& Staw, B. M. (1997). The tradeoffs of social control and innovation in groups and organizations. In L. Berkowitz (Ed.), Advances in Experimental Social Psychology (Vol. 22, pp. 175-210). New York: Academic Press.

Pinder, C. C., \& Harlos, K. P. (2001). Employee silence: Quiescence and acquiescence as responses to perceived injustice. In K. M. Rowlandand, \& G. R. Ferris (Eds.), Research in personnel and Human Resources Management (pp. 331-369). New York. https://doi.org/10.1016/s0742-7301(01)20007-3

Vakola, M., \& Bouradas, D. (2005). Antecedents and consequences of organizational silence: An empirical investigation. Employee Relations, 27(5), 441-458. https://doi.org/10.1108/01425450510611997

\section{Copyrights}

Copyright for this article is retained by the author(s), with first publication rights granted to the journal.

This is an open-access article distributed under the terms and conditions of the Creative Commons Attribution license (http://creativecommons.org/licenses/by/4.0/). 